Research Paper

\title{
Distinct Effects of RGD-glycoproteins on Integrin-Mediated Adhesion and Osteogenic Differentiation of Human Mesenchymal Stem Cells
}

\author{
Elisabeth H. Schwab1 *, Maria Halbig ${ }^{*}$, Kristina Glenske², Alena-Svenja Wagner², Sabine Wenisch², \\ Elisabetta A. Cavalcanti-Adam ${ }^{1 凶}$ \\ 1. Department of Biophysical Chemistry, Institute for Physical Chemistry, University of Heidelberg, INF 253, 69120 Heidelberg, Germany \& Max \\ Planck Institute for Intelligent Systems, Heisenbergstr. 3, 70569 Stuttgart, Germany; \\ 2. Institute of Veterinary -Anatomy, -Histology, and -Embryology, Justus-Liebig University, Frankfurter Str. 98, 35392 Giessen, Germany. \\ * These authors contributed equally to this work.
}

$\square$ Corresponding author: Elisabetta Ada Cavalcanti-Adam, DMD, PhD. University of Heidelberg, Institute for Physical Chemistry, Dept. of Biophysical Chemistry, Im Neuenheimer Feld 253, 69120 Heidelberg, Germany. Tel.: $\quad+49 \quad 622154 \quad 5064$ Fax: $\quad+49 \quad 6221 \quad 54 \quad 4950 \quad$ Email: ada.cavalcanti-adam@urz.uni-heidelberg.de.

(c) Ivyspring International Publisher. This is an open-access article distributed under the terms of the Creative Commons License (http://creativecommons.org/ licenses/by-nc-nd/3.0/). Reproduction is permitted for personal, noncommercial use, provided that the article is in whole, unmodified, and properly cited.

Received: 2013.06.14; Accepted: 2013.10.05; Published: 2013.11.09

\begin{abstract}
The detailed interactions of mesenchymal stem cells (MSCs) with their extracellular matrix (ECM) and the resulting effects on MSC differentiation are still largely unknown. Integrins are the main mediators of cell-ECM interaction. In this study, we investigated the adhesion of human MSCs to fibronectin, vitronectin and osteopontin, three ECM glycoproteins which contain an integrin-binding sequence, the RGD motif. We then assayed MSCs for their osteogenic commitment in the presence of the different ECM proteins.

As early as 2 hours after seeding, human MSCs displayed increased adhesion when plated on fibronectin, whereas no significant difference was observed when adhering either to vitronectin or osteopontin. Over a I0-day observation period, cell proliferation was increased when cells were cultured on fibronectin and osteopontin, albeit after 5 days in culture. The adhesive role of fibronectin was further confirmed by measurements of cell area, which was significantly increased on this type of substrate. However, integrin-mediated clusters, namely focal adhesions, were larger and more mature in MSCs adhering to vitronectin and osteopontin. Adhesion to fibronectin induced elevated expression of $\alpha_{5}$-integrin, which was further upregulated under osteogenic conditions also for vitronectin and osteopontin. In contrast, during osteogenic differentiation the expression level of $\beta_{3}$-integrin was decreased in MSCs adhering to the different ECM proteins. When MSCs were cultured under osteogenic conditions, their commitment to the osteoblast lineage and their ability to form a mineralized matrix in vitro was increased in presence of fibronectin and osteopontin.

Taken together these results indicate a distinct role of ECM proteins in regulating cell adhesion, lineage commitment and phenotype of MSCs, which is due to the modulation of the expression of specific integrin subunits during growth or osteogenic differentiation.
\end{abstract}

Key words: mesenchymal stem cells, extracellular matrix, osteogenic differentiation, integrins, cell adhesion.

\section{Introduction}

Adult mesenchymal stem cells (MSC) are a popcated within the bone marrow and cartilage, and to a ulation of non-hematopoietic, multipotent cells lo-

lesser extent also in other tissues of mesenchymal 
origin (1). Upon specific stimuli, MSCs can differentiate into at least three different lineages: osteoblasts (2), chondroblasts and adipocytes $(3,4)$. Following injuries, such as bone fractures, MSCs migrate from their niche to sites of tissue damage, thereby locally supporting the process of healing (5). Hence, MSCs are good candidates for tissue regeneration strategies in human during bone and fracture healing. However, the effectiveness of bone regeneration processes depends on the balance between events that regulate cell proliferation and differentiation (6).

In bone marrow, MSCs are located in the so called "stem cell niche", a unique and dynamic microenvironment directly influencing their fate. The niche encloses non-stem cells, extracellular matrix (ECM) proteins and soluble molecules surrounding and interacting with MSCs. Various soluble factors, e.g. dexamethasone, bone morphogenetic protein-2 (BMP-2), $\beta$-glycerophosphate and ascorbic acid, have been identified as potent inducers of in vitro osteogenic differentiation $(7,8)$. The niche can also trigger proliferation and differentiation through changes in its architecture $(1,9,10)$. Little is known however about the influence of specific interactions between ECM proteins and MSCs; in particular, the role of cell adhesion to the ECM in regulating the osteogenic differentiation process still remains poorly understood.

Bone marrow ECM comprises several protein families, including collagens, proteoglycans, and glycoproteins $(11,12)$. The glycoproteins fibronectin $(\mathrm{FN})$, vitronectin $(\mathrm{VN})$ and osteopontin $(\mathrm{OPN})$ contain within their structure an integrin-binding motif, the Arg-Gly-Asp (RGD) sequence. Integrins are a class of heterodimeric cell surface receptors and consist of two non-covalently associated transmembrane protein subunits ( $\alpha$ and $\beta$ ) with large extracellular and short intracellular domains (13). To date, 24 different subunit combinations with varying specificities towards ECM proteins have been identified (14). Integrins form a direct linkage between the ECM and the actin cytoskeleton (15). Upon binding to ECM proteins, the resulting intracellular signaling cascades modulate cell phenotype and genotype, thereby affecting adhesion, proliferation and differentiation (16-21). In turn, changes in the expression of integrins and cytoskeletal proteins (22) during stem cell commitment play an important role in the control of cell phenotype.

Several studies suggest that cues from the ECM regulate not only cell adhesion and migration but also differentiation by activating specific integrin subunits and heterodimers (23-26). Interestingly, Hamidouche et al. (26) showed that the expression of a $a_{5}$-integrin is upregulated in MSCs under osteogenic conditions and that activation of this subunit is sufficient to induce osteoblastic differentiation. In addition, Schnei- der et al. (25) suggested that adhesion and signaling via $\alpha_{v} \beta_{3}$-integrin might be required for osteoblastic differentiation. Although these reports show evidence that integrin-mediated adhesion influences and regulates osteoblastic differentiation, some of the results are still a matter of debate (23). In particular, the specific role of different integrins in MSC differentiation remains unclear. Moreover, it is still unknown whether initial attachment and spreading of cells due to integrin binding to RGD motifs of different ECM glycoproteins may affect cell commitment.

In this study we investigate the impact of the microenvironment on the functional behavior of human MSCs. We focus on the specific contribution of $\alpha_{v} \beta_{3}$ and $\alpha_{5} \beta_{1}$ integrins to early adhesion-mediated events of MSCs on fibronectin, vitronectin and osteopontin, including adhesion, spreading and proliferation, as well as on the effects of the RGD-glycoproteins on osteogenic commitment.

\section{Material and Methods}

\section{Culture of human MSCs}

MSCs isolated from human bone marrow of an adult donor (male, 64, bone marrow from femoral head) were purchased from Promocell (Heidelberg, Germany). Cells were maintained in culture in growth medium (Promocell), $5 \% \mathrm{CO}_{2}$-atmosphere at $37^{\circ} \mathrm{C}$ and the medium was renewed every 2-3 days. Upon reaching $70-80 \%$ confluence, cells were detached by Accutase treatment (Gibco, Life Technologies, Darmstadt, Germany) and subcultured at a dilution of 1:3. All experiments were conducted using cells below passage 5.

Experimental data were collected using cells cultured in either standard growth medium or in osteogenic differentiation medium (Promocell).

\section{ECM glycoproteins and coating procedure}

For all functional assays substrates were coated with vitronectin (VN, human plasma, $0.5 \mu \mathrm{g} / \mathrm{cm}^{2}$, Sigma, Steinheim, Germany), fibronectin (FN, human plasma, $4 \mu \mathrm{g} / \mathrm{cm}^{2}$, Sigma) and osteopontin (OPN, human recombinant expressed in NSO cells, 0.5 $\mu \mathrm{g} / \mathrm{cm}^{2}$, Sigma) diluted in $1 \mathrm{x}$ phosphate buffered saline (PBS, pH 7.2, PAA, Coelbe, Germany) or water according to the manufacturers' recommendations. Poly-L-lysine (PLL, 70-150 kDa, $2 \mu \mathrm{g} / \mathrm{cm}^{2}$, Sigma) was used as control. The different amounts ensured the complete coating of the surface for each type of ECM protein. Tissue culture treated polystyrene surfaces or glass coverslips were coated with the ECM protein solution overnight at $4{ }^{\circ} \mathrm{C}$, washed twice with PBS, blocked with $1 \%$ bovine serum albumin (BSA, Sigma) in PBS for $10 \mathrm{~min}$ at room temperature and sterilized with UV light for $30 \mathrm{~min}$. 


\section{Adhesion assay}

For analysis of cell adhesion, $4.5 \times 10^{3}$ cells $/ \mathrm{cm}^{2}$ were seeded in single wells of a 48-well plate and allowed to attach for 2 or $4 \mathrm{~h}$, respectively. Then, cells were washed once with PBS to remove non-adherent cells, followed by addition of fresh medium. After incubation for 2 or $4 \mathrm{~h}$ in presence of $10 \% \mathrm{v} / \mathrm{v}$ CellTiter-Blue reagent ${ }^{\circledR}$ (Promega, Madison, USA), the number of attached cells was determined. Therefore, the transformation of the blue non-fluorescent dye resazurin into the red fluorescent resorufin $\left(\lambda_{\mathrm{ex}}=530 \mathrm{~nm} ; \lambda_{\mathrm{em}}=590 \mathrm{~nm}\right)$ was measured spectroscopically with a plate reader (Infinite 200, Tecan, Maennedorf, Switzerland) using $530 \mathrm{~nm}$ excitation and $600 \mathrm{~nm}$ emission filters with a counting time of $200 \mu \mathrm{s}$. For the different surfaces, cell adhesion experiments were repeated twice in 3 replicates.

The number of cells on coated surfaces at later time points $(1,5$ or 10 days after seeding) was determined by counting DAPI-stained cell nuclei. All data were normalized to control conditions, i.e. MSCs on PLL-coated substrates.

\section{5-ethynyl-2'-deoxyuridine (EdU) incorporation and indirect immunofluorescence staining}

MSCs were seeded and incubated on the different substrates for $4 \mathrm{~h}, 1,5$ and 10 days in either standard growth or osteogenic differentiation medium. For EdU incorporation experiments, EdU (from the Click-iT® EdU Alexa Fluor ${ }^{\circledR} 647$ Imaging Kit, Life Technologies) was added at a $50 \mu \mathrm{M}$ final concentration $24 \mathrm{~h}$ before the indicated time points to allow incorporation into DNA during active synthesis. After removing the culture medium, the wells were rinsed three times with PBS. The cells were fixed with $4 \%$ paraformaldehyde for $30 \mathrm{~min}$ at room temperature and rinsed with PBS once. Fixed cells were permeabilized with PBS-0.1\% Triton-X 100 (Sigma) for $10 \mathrm{~min}$. To reduce non-specific binding, samples were blocked with $1 \%$ BSA in PBS for $10 \mathrm{~min}$ at room temperature. After additional washings, cells were incubated for $30 \mathrm{~min}$ with Click-iT reaction cocktail containing Alexa Fluor 647-azide to detect EdU and washed afterwards with $3 \%$ BSA/PBS solution.

After blocking, samples were incubated with anti-vinculin mouse monoclonal antibody $(1-10 \mu \mathrm{g} / \mathrm{ml}$, Sigma) for $1 \mathrm{~h}$ at room temperature. Upon removal of the unbound antibody by washing with PBS, cells were incubated with Alexa Fluor 488-labeled goat anti-mouse secondary antibody $(10-20 \mu \mathrm{g} / \mathrm{ml}$, Life Technologies) and TRITC-conjugated phalloidin ( $1 \mu \mathrm{g} / \mathrm{ml}$, Sigma) for an additional hour at room temperature. Please note that the EdU assay is not compatible with the Phalloidin staining protocol. Cell nuclei were then stained with
DAPI $(1 \mu \mathrm{g} / \mathrm{ml}$, Sigma) for $5 \mathrm{~min}$ at room temperature.

\section{Microscopy and image analysis}

Immunofluorescence as well as phase contrast microscopy was carried out on a Delta Vision RT system (Applied Precision Inc., Issaquah, USA) consisting of an Olympus IX inverted microscope (Olympus, Hamburg, Germany).

For cell proliferation analysis, a panel collection of hundred, not overlapping images (1024 x 1024 pixels) per surface was taken with a $10 \times$ magnification air objective lens (Neofluor 10x/0.3 phase contrast, Carl Zeiss, Jena, Germany). Applying two different filters (DAPI, Cy5) pictures of proliferating and total nuclei number were taken. Actively proliferating cells (Alexa Fluor 647-positive cell nuclei) were counted using the particle analyzer plugin of ImageJ software (http://rsb.info.nih.gov/ij/; version $1.47 \mathrm{n}$ ) and normalized to total cell number (DAPI stained cell nuclei).

The projected cell area was evaluated $4 \mathrm{~h}, 1 \mathrm{~d}$ and $5 \mathrm{~d}$ after seeding on coated substrates using a $10 \mathrm{x}$ air objective and analyzed with ImageJ. 25 images per surface containing at least 3 entirely visible cells were taken and cell area was measured as described below for focal adhesion analysis.

Focal adhesions (FAs) were imaged using a $60 \mathrm{x}$ oil objective (PlanApo 60x/1.4 Olympus). For the analysis of focal adhesion number, area and long axis, a self-written ImageJ macro including the following steps was applied to each image: creation of an 8-bit image followed by background subtraction and contrast adjustment. Thresholding then resulted in a binary image. FA size and long axis were determined using the "analyze particles" plugin within a preset size range $0.5 \mu \mathrm{m}^{2}-10 \mu \mathrm{m}^{2}$ and a circularity of $0-1$. Images were adjusted for brightness and color for presentation. At least 10 cells per group were analyzed. Experiments were performed in three technical repeats.

\section{Western blot analysis of integrins}

Detection of total protein levels of integrin subunits in MSCs was performed by SDS-PAGE gel electrophoresis and western blot analysis. Briefly, MSCs were seeded in culture plates coated with ECM proteins in either standard growth or osteogenic media. Cells were lysed after 1,5 and 10 days in $1 \%$ IGEPAL CA-630, $0.25 \%$ sodium deoxycholate, $667 \mathrm{mM}$ EDTA, $100 \mathrm{mM}$ PMSF, $200 \mathrm{mM} \mathrm{Na}_{3} \mathrm{VO}_{4}$, $150 \mathrm{mM} \mathrm{NaCl}$ (all from Sigma), $50 \mathrm{mM}$ Tris- $\mathrm{HCl}$ (Biomol, Hamburg, Germany), and protease inhibitors (Complete Mini, Roche). Lysates were cleared by centrifugation at $10000 \mathrm{rpm}$ for $10 \mathrm{~min}$ at $4{ }^{\circ} \mathrm{C}$. The 
total protein concentration of the supernatant was determined using a BCA protein assay kit (Pierce Biotechnology, Inc., Rockford, USA). Equal protein amounts were separated by SDS-PAGE, transferred to a PVDF membrane and then probed with one of the following primary antibodies (all mouse IgG, $1 \mu \mathrm{g} / \mathrm{ml}$ ) overnight at $4{ }^{\circ} \mathrm{C}$ (all from BD Transduction Laboratories $^{\mathrm{TM}}$, BD Biosciences, San Diego, USA): anti-CD51, anti-CD61, anti-CD49e, anti-CD29. Incubation with goat anti-mouse HRP-conjugated IgG $(0.1 \mu \mathrm{g} / \mathrm{ml}$, Santa Cruz Biotechnology, Inc., Dallas, USA) was followed by detection with ECL Plus Detection Kits (GE Healthcare, Uppsala, Sweden).

\section{RNA Isolation and quantitative real-time PCR}

$1 \times 10^{5}$ cells were seeded in either standard growth or osteogenic differentiation medium into coated 6-well plates and cultured for 1, 5 or 10 days, respectively. Total RNA was extracted using peqGOLD TriFast (Peqlab, Erlangen, Germany) according to the manufacturer's instructions. The concentration of extracted RNA was measured with a ND-2000 UV spectrometer (Nanodrop, Wilmington, Germany) and $1.5 \mu \mathrm{g}$ of each RNA sample was used to synthesize the corresponding cDNA. For the relative quantification of mRNA expression qRT-PCR was performed using QuantiFast SYBR Green PCR Kit (Qiagen, Hilden, Germany) and QuantiTect Primer Assays (Qiagen) with the BioRad CFX96 Touch Real-Time PCR Detection System (Bio-Rad Laboratories, München, Germany).

$2 \mu \mathrm{l}$ cDNA $(100 \mathrm{ng} / \mu \mathrm{l})$ and $10 \mu \mathrm{l}$ QuantiFast SYBR Green PCR Master Mix combined with $2 \mu \mathrm{l}$
QuantiTect Primer and $6 \mu$ RNAse free water were used for each sample.

After 5 min of pre-incubation at $95^{\circ} \mathrm{C}, 40$ amplification cycles were performed; each cycle consisted of the following steps: $10 \mathrm{sec}$ at $95{ }^{\circ} \mathrm{C}$ and $30 \mathrm{sec}$ at $60^{\circ} \mathrm{C}$. Additionally melting curve analysis (from $60^{\circ} \mathrm{C}$ to $95^{\circ} \mathrm{C}$, increment $0.5^{\circ} \mathrm{C}$ ) was done to prove specificity. All genes were tested in triplets for every sample. A no-template-control (NTC) and calibrator were carried along for every gene. The mRNA expression levels of the target genes were normalized to GAPDH and 185 mRNA levels, and all data were analyzed using the $\Delta \Delta$ Ct-method (BioRad CFX Manager $^{\mathrm{TM}}$ Software version 2.1 and 3.0).

\section{Histological staining}

Osteogenic differentiation was monitored using a standard matrix mineralization assay. Alizarin Red $S$ (Sigma) was used to detect calcium mineralization in MSCs cultured onto substrates coated with ECM proteins and standard or osteogenic medium for 21 days. Cells were washed 3 times with $\mathrm{PBS}$ and $\mathrm{ddH}_{2} \mathrm{O}$ and incubated with $2 \%(\mathrm{w} / \mathrm{v})$ Alizarin Red solution for 2-5 min at room temperature. Cells were washed afterwards with $\mathrm{ddH}_{2} \mathrm{O}$ to remove excess staining and fixed in $4 \%$ PFA in PBS for preservation.

\section{Statistical analysis}

Results from three independent experiments are displayed as mean \pm standard deviation and were analyzed for statistical significance using the two-tailed unpaired student's t-test or Mann-Whitney $\mathrm{U}$ test with a significance level of $\mathrm{p}<0.05$.

Table I. QuantiTect Primer Assays

\begin{tabular}{lll}
\hline Genes & Abbrev. & QuantiTect Primer Assays \\
\hline Alkaline phosphatase & ALP & QT00012957 \\
Integrin binding sialo protein & BSP & QT00093709 \\
runt-related transcription factor 2 & Runx2 & QT00020517 \\
Integrin $\alpha_{v}$ & $a_{v}$ & QT00051891 \\
Integrin $\alpha_{5}$ & $a_{5}$ & QT00080871 \\
Integrin $\beta_{1}$ & $\beta_{1}$ & QT00068124 \\
Integrin $\beta_{3}$ & $\beta_{3}$ & QT00044590 \\
Glycerinaldehyde-3-phosphate-Dehydrogenase & GAPDH & QT01192646(Reference Gene) \\
18 ribosomal RNA & $18 S$ & QT00199367(Reference Gene) \\
\hline
\end{tabular}

\section{Results}

\section{Initial cell attachment and proliferation are increased on FN-coated surfaces}

For adhesion assays, cells were plated on the different substrates and the number of attached cells was determined 2 and 4 hours after seeding. After 2 hours, human MSC adhesion is significantly enhanced on FN compared to $\mathrm{VN}$ and OPN coatings under standard growth conditions ( $p>0.01)$ (Fig. 1A). The same tendency is observed under osteogenic conditions; however, adhesion can be considered as significantly enhanced only when FN coatings are compared to OPN-coated surfaces ( $p>0.01$ ). After 4 hours, cell adhesion on FN is significantly increased 
when compared to the control ( $p>0.01)$ (Fig. 1B). A highly significant increase in adhesion to $\mathrm{FN}$ is observed in comparison to VN and OPN ( $p>0.001)$

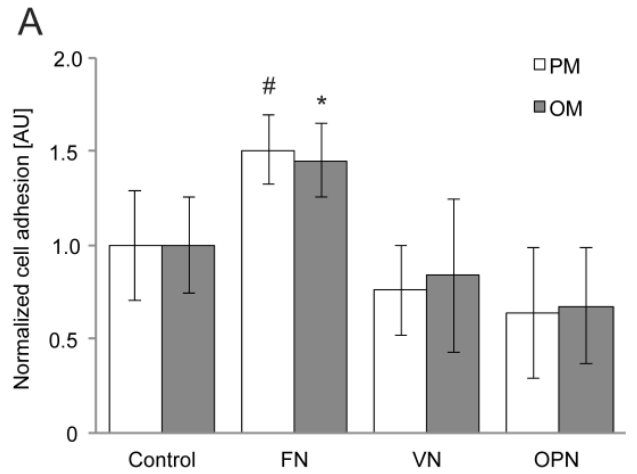

under growth conditions, whereas no statistical significant difference is observed under osteogenic conditions.

B

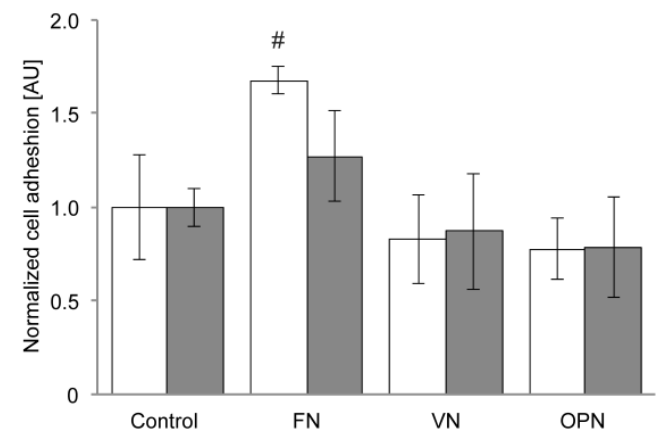

Fig I. hMSC adhesion on substrates coated with RGD-glycoproteins. The number of adherent cells was evaluated by measuring the optical density from CellTiter-Blue staining of cells (A) $2 \mathrm{~h}$ and (B) $4 \mathrm{~h}$ after seeding. Cell number is increased on FN coatings at both time points. PM, proliferation (=growth) media; OM, osteogenic media. *, \# indicate statistical significance $(P<0.05)$

Fig 2. Analysis of hMSC proliferation on extracellular matrix-coated substrates. (A) day I; (B) day 5; (C) day 10. Proliferation rates are increased on FN and OPN compared to control after 5 and 10 days of cultivation. In all cases hMSC proliferation is elevated under standard growth conditions compared to osteogenic differentiation conditions. * indicates statistical significance $(\mathrm{p}<0.05)$ (PM compared to OM per coating); $\#$ and $\S$ indicate statistical significance of proliferation rates obtained on different substrates compared to Control (PLL-coated substrates) in PM or OM, respectively $(p<0.05)$

Similarly, due to enhanced adhesion, the number of cells on FN-coated surfaces is slightly higher after 1 day compared to other surfaces in growth medium whereas no differences are observed in osteogenic medium (Supplementary Material: Fig. S1). To analyze the influence of ECM proteins on MSC proliferation under growth or differentiation conditions respectively, the number of proliferating cells was evaluated at 1, 5 and 10 days after cell seeding. Compared to standard growth conditions, proliferation rates are significantly reduced under osteogenic conditions for all the time points (Fig. 2A-C). After 5 days, a highly significant increase in the proliferation rate of cells on FN and OPN under both conditions is observed in comparison to PLL ( $p<0.0001)$. Cells on VN display a significantly higher proliferation rate under osteogenic conditions but a reduced proliferation rate under growth conditions compared to control $(\mathrm{p} \leq 0.0005)$ (Fig. 2B). At day 10, proliferation rates under standard conditions are enhanced on $\mathrm{FN}$ and OPN compared to control $(\mathrm{p}<0.0005)$ and on all surfaces a highly significant reduction of proliferation is observed in differentiation media $(\mathrm{p}<0.0001)$ (Fig. 2C).

\section{Cell area is increased on FN coatings whereas larger focal adhesions are observed on VN- and OPN-coated surfaces}

Morphologically, MSCs isolated from human bone marrow are a heterogeneous population of cells
A

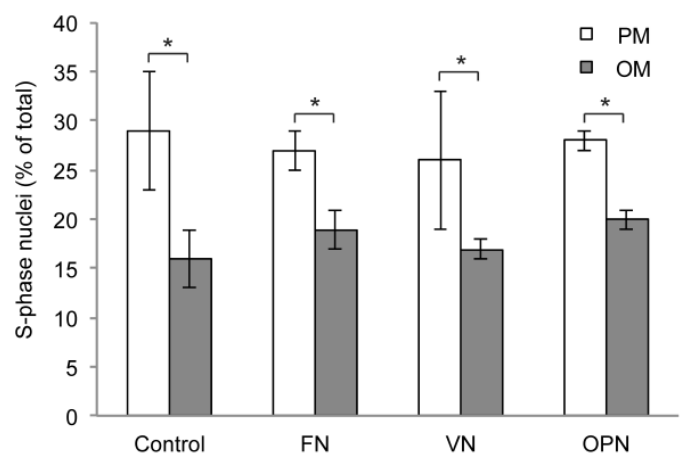

B

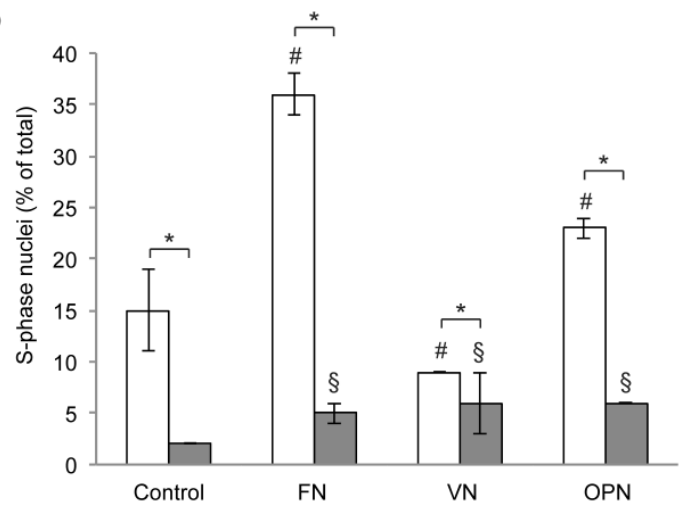

C

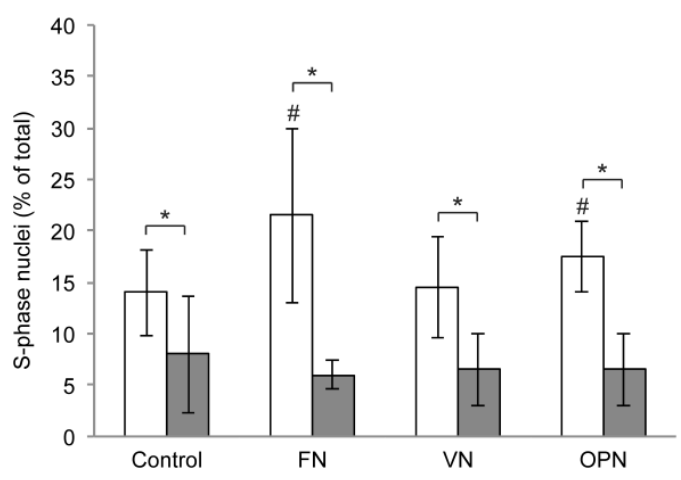


(27-29). As classified by the Prockop group, MSC cultures can be divided into at least two morphological types under standard culture conditions: rapidly self-renewing, round or spindle-shaped cells and slowly replicating, cuboidal or flattened cells (28,30-33). While rapidly self-renewing cells exhibit an average area of $3000-5000 \mu \mathrm{m}^{2}$, the slowly replicating MSCs display a larger cell area (34).

It has also been reported that cell shape and size, actin cytoskeleton and osteogenic potential are closely related (35). We therefore determined the cell area of MSCs grown on ECM coated-surfaces under growth and differentiation conditions (Fig. 3A,B). Cells on control surfaces exhibit almost exclusively an elongated spindle-shape, with a cell area smaller than $5000 \mu \mathrm{m}^{2}$, thereby indicating reduced adhesion. The number of small cells on FN, VN and OPN decreased over time, independently of the type of media (Fig. $3 \mathrm{~A})$. Compared to the control, cells on ECM coated-surfaces become flattened and more spread (cell area $>5000 \mu \mathrm{m}^{2}$ ) under both conditions. After 4 hours, 1 and 5 days in culture with differentiation media, a significantly higher number of cells on FN and OPN exhibits an area $>5000 \mu \mathrm{m}^{2}$ compared to their respective in standard conditions $(\mathrm{p}<0.0005)$. A similar amount of cells displaying an area $>5000 \mu \mathrm{m}^{2}$ is observed on VN under both conditions after 5 days (Fig. 3B).

To gain insight into the cytoarchitecture responsible for differences in cell area, we imaged the actin cytoskeleton using TRITC-Phalloidin. MSCs cultured in osteogenic differentiation media present thicker actin stress fibers, while cells under growth conditions exhibit a more disperse actin cytoskeleton (Supplementary Material: Fig. S2). Due to the marked changes observed regarding cell size and shape, as well as the distinct organization of the actin cytoskeleton, we next examined whether cell structures involved in integrin-mediated adhesion, namely focal adhesions, were modulated by the type of substrate. Upon binding via their extracellular domains to the ECM, integrins cluster and their cytoplasmic tails associate with cytoskeletal and intracellular signal transduction molecules forming macromolecular aggregates known as focal adhesions (FAs) (12). Vinculin immunostaining was used to label FAs. After 4 and 24 hours in culture, MSCs on ECM-coated surfaces show large, discrete clusters while no complexes can be seen in cells on control surfaces (Fig. 4A-D). Four hours after seeding, cells cultured on FN in osteogenic media reveal a significantly higher number of FAs per cell compared to cells under growth conditions; a similar behavior is observed in MSCs on VN and OPN under differentiation conditions ( $p<0.005)$ (Fig. 4E). However, cells on FN display smaller FAs compared to cells cultured on VN and OPN under both conditions ( $\mathrm{p}$ <.0001). Moreover, in MSCs on FN and VN FAs are significantly smaller under differentiation conditions compared to growth conditions $(\mathrm{p}<0.0001)$ (Fig. 4G).

After one day, the number of total FAs per cell is significantly increased in cells cultured on FN compared to other ECM coatings under growth conditions $(p>0.01)$ but comparable on all ECM protein coatings under differentiation conditions (Fig. 4F). The FA size is still significantly decreased in cells on FN compared to the other ECM coatings under growth conditions $(\mathrm{p}<0.0001)$ while cells on VN display the largest average area of FA clusters compared to FN and OPN under differentiation conditions $(\mathrm{p}<0.01)($ Fig. $4 \mathrm{H})$.

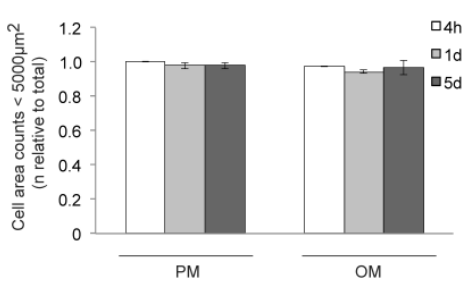

B

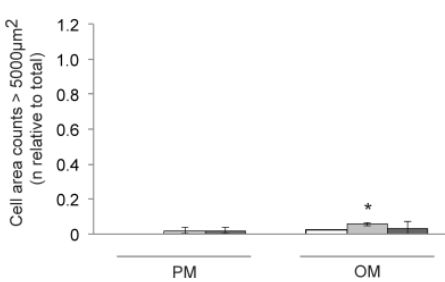

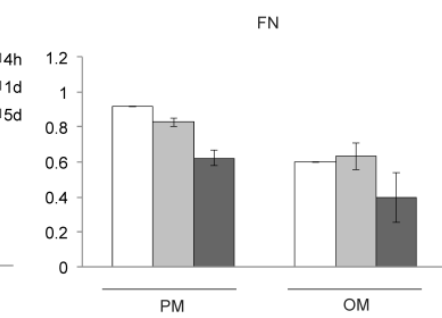
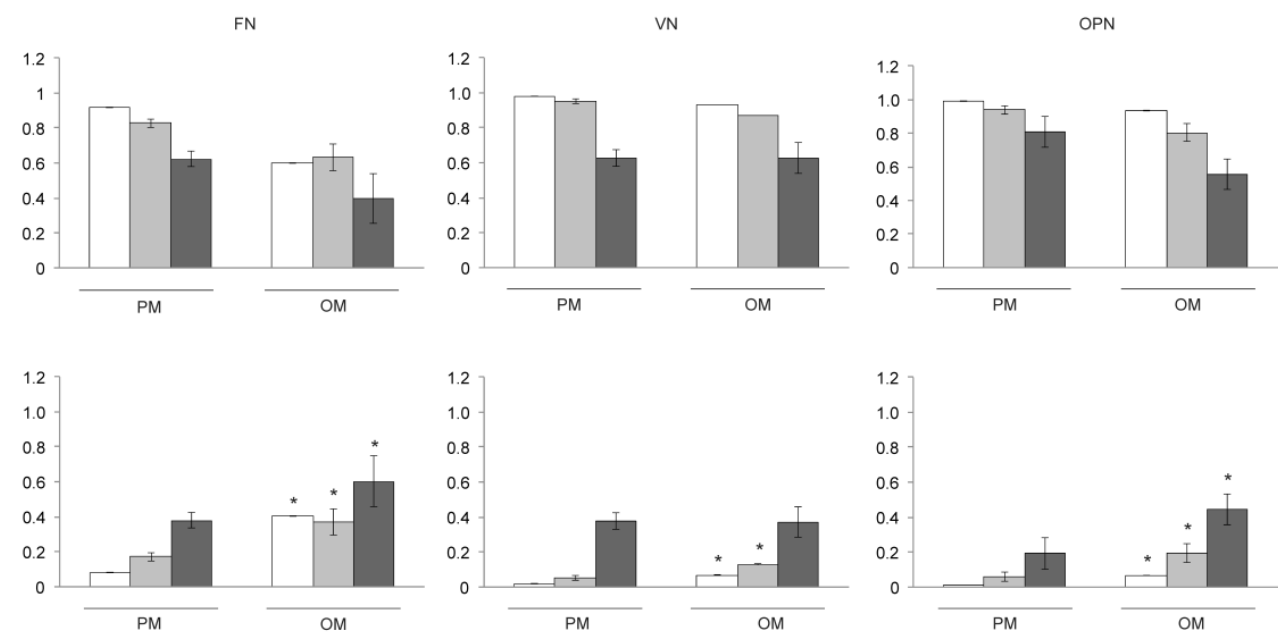

Fig 3. Cell size of hMSCs on ECM protein-coated substrates under standard growth and osteogenic differentiation conditions. Number of cells (relative to total cell number) with a cell area (A) $<5000 \mu \mathrm{m}^{2}$ and (B) $>5000 \mu \mathrm{m}^{2}$ on different coatings $4 \mathrm{~h}, \mathrm{I} \mathrm{d}$ and $5 \mathrm{~d}$ after seeding. A larger fraction of cells on FN exhibits an increased cell size compared to other ECM coatings after $4 \mathrm{~h}$ and $5 \mathrm{~d}$. Under osteogenic differentiation conditions cell size is increased on all ECM protein-coated substrates compared to standard growth conditions. * indicates statistical significance compared to standard growth conditions ( $P<0.05$ ) 
A

A

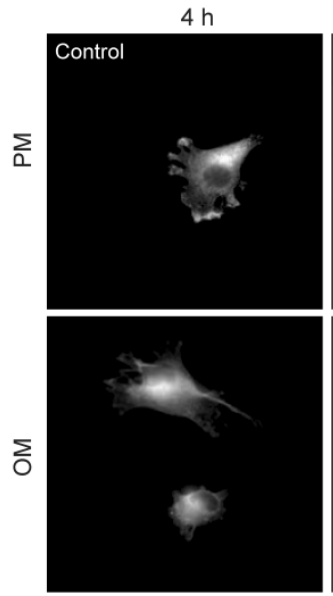

C
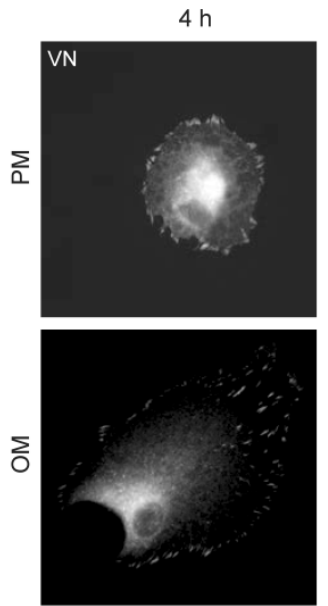

E

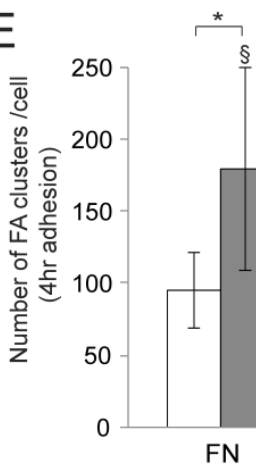

G
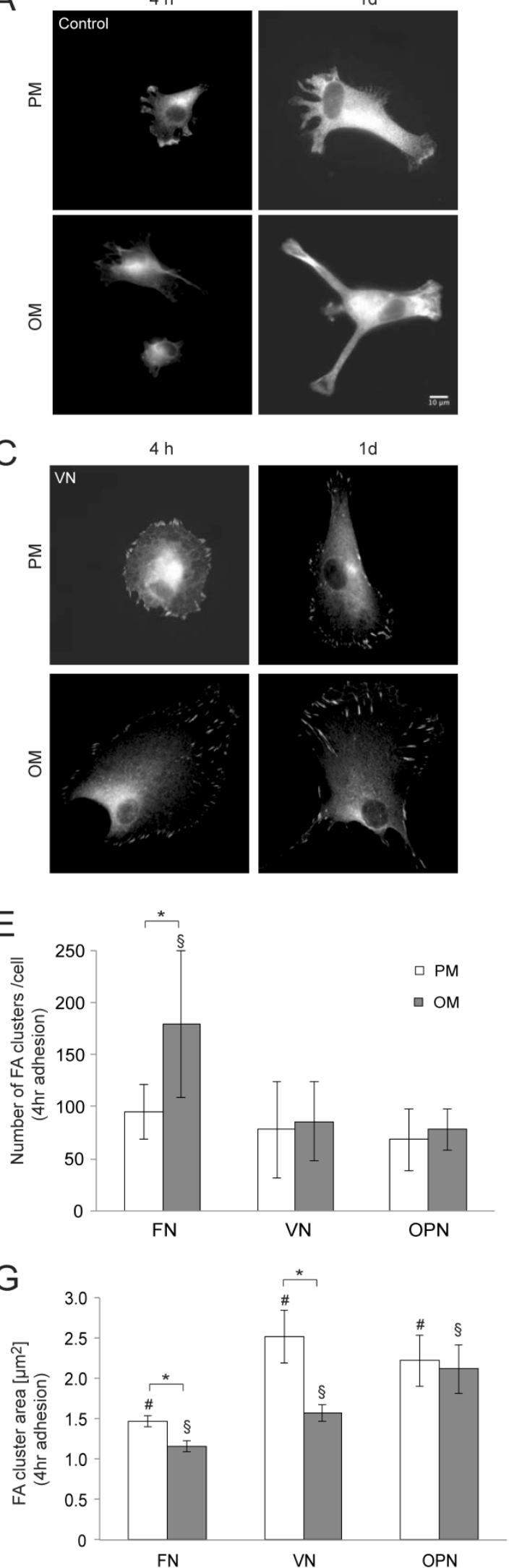

$1 d$
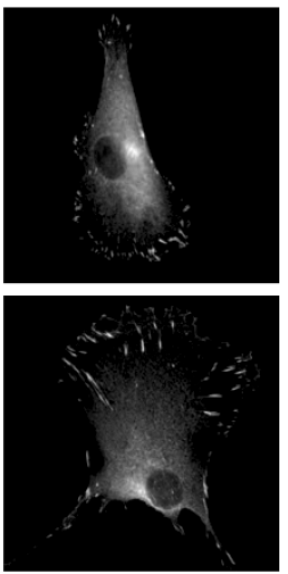

$\square$ PM

口 OM

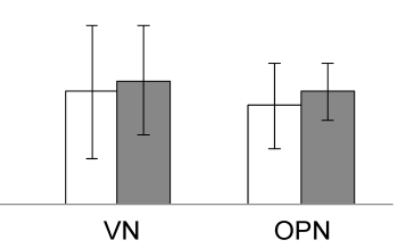

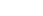

B 


\section{$\alpha_{5}$-integrin expression is increased on $\mathrm{FN}$ and under osteogenic conditions}

Most integrins bind to several ECM molecules and conversely, most ECM bind to more than one integrin heterodimer. However, specific combinations of integrin $\alpha$ and $\beta$ subunit result in different binding specificity (15). To investigate the role of $\alpha_{v}, \alpha_{5}, \beta_{1}$ and $\beta_{3}$ integrin subtypes in adhesion and differentiation, temporal changes in cell integrin profiles at gene expression and protein level were evaluated.

Gene expression profiles of MSC cultured on ECM protein-coated surfaces revealed elevated levels of integrin subunits $a_{V}$ and $a_{5}$ under osteogenic differentiation conditions, while both subunits are downregulated under growth conditions. This trend is also observed to a lesser extent on the control surfaces. In particular, higher levels of $a_{5}$ are expressed in cells adhering to FN while cells on OPN express higher amounts of $a_{\mathrm{V}}$ after 1 and 10 days. Expression of integrin subunit $\beta_{1}$ does not significantly vary among protein-coated surfaces or under different culture conditions. In contrast, expression of integrin subunit $\beta_{3}$ is clearly reduced under osteogenic conditions compared to growth conditions on all surfaces (Fig. 5A).

Additionally, western blot analysis was used to investigate integrin profiles on protein level within MSCs cultured on ECM proteins. After one day in culture, elevated levels of integrin subunit $a_{5}$ under osteogenic conditions on all surfaces but especially on FN are observed. After 5 and 10 days, higher levels of integrin subunits $\alpha 5$ and $a_{v}$ are detected in cells cultured on ECM proteins under osteogenic conditions compared to proliferation conditions. Analysis of both $\beta$ subunits reveal the same trends compared to gene expression levels: while $\beta_{1}$ protein levels are comparable on all surfaces under both conditions, $\beta_{3}$ protein levels are decreased in cells cultured under osteogenic differentiation conditions compared to proliferation conditions (Fig. 5B-D).
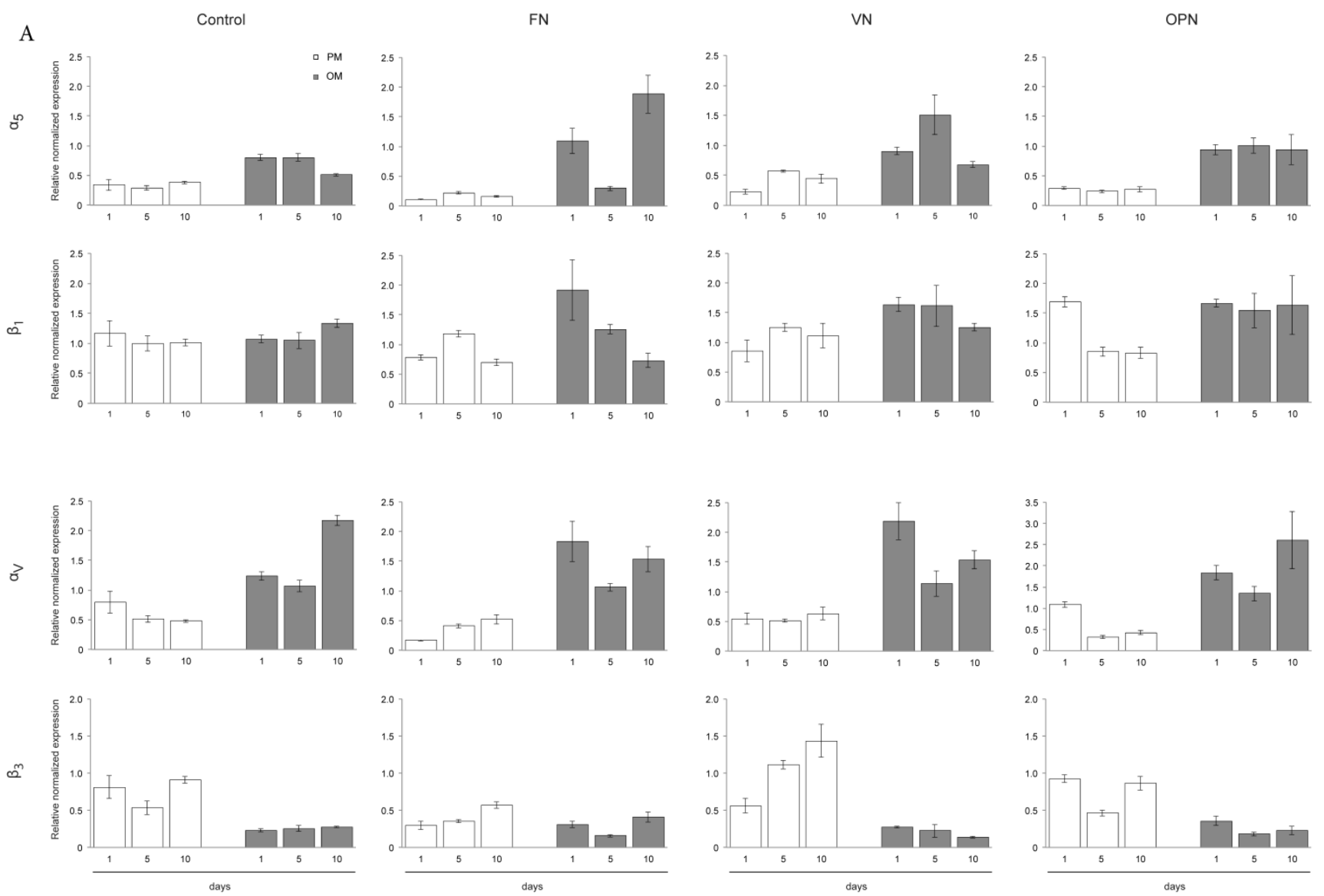
B
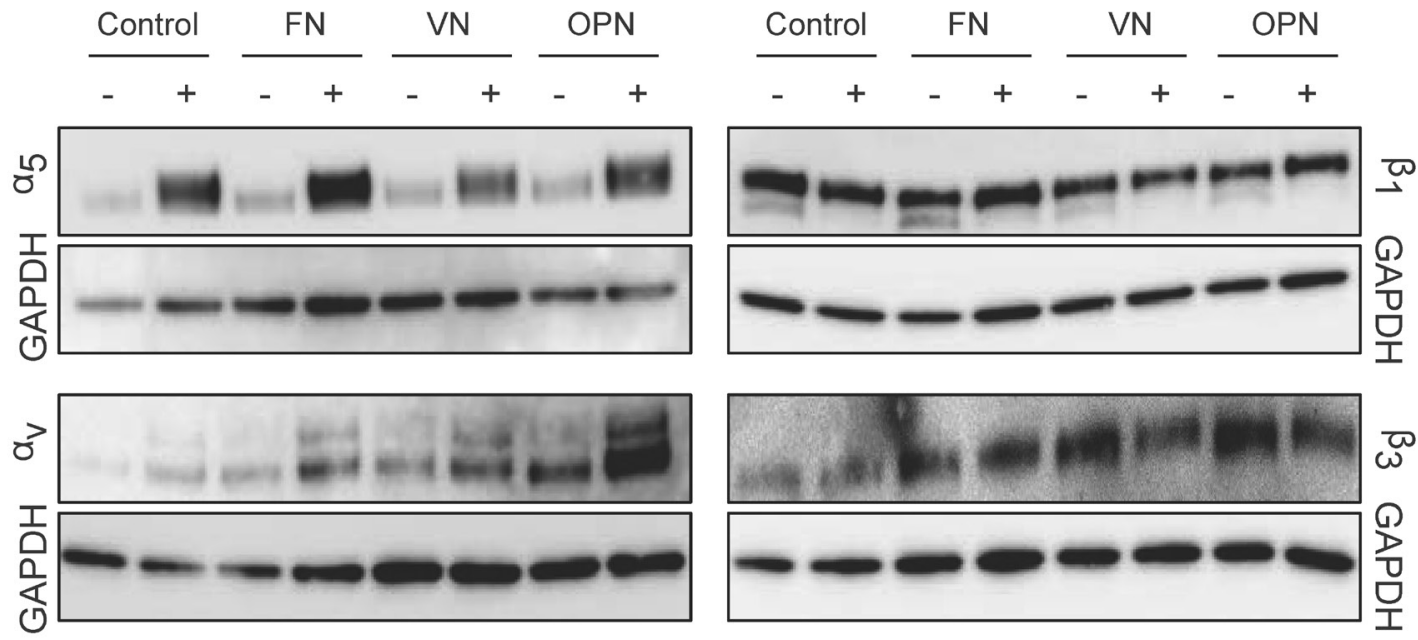

C $\frac{\text { Control }}{-++} \frac{\text { FN }}{-++} \frac{\text { VN }}{-\quad+} \frac{\text { OPN }}{-++}$
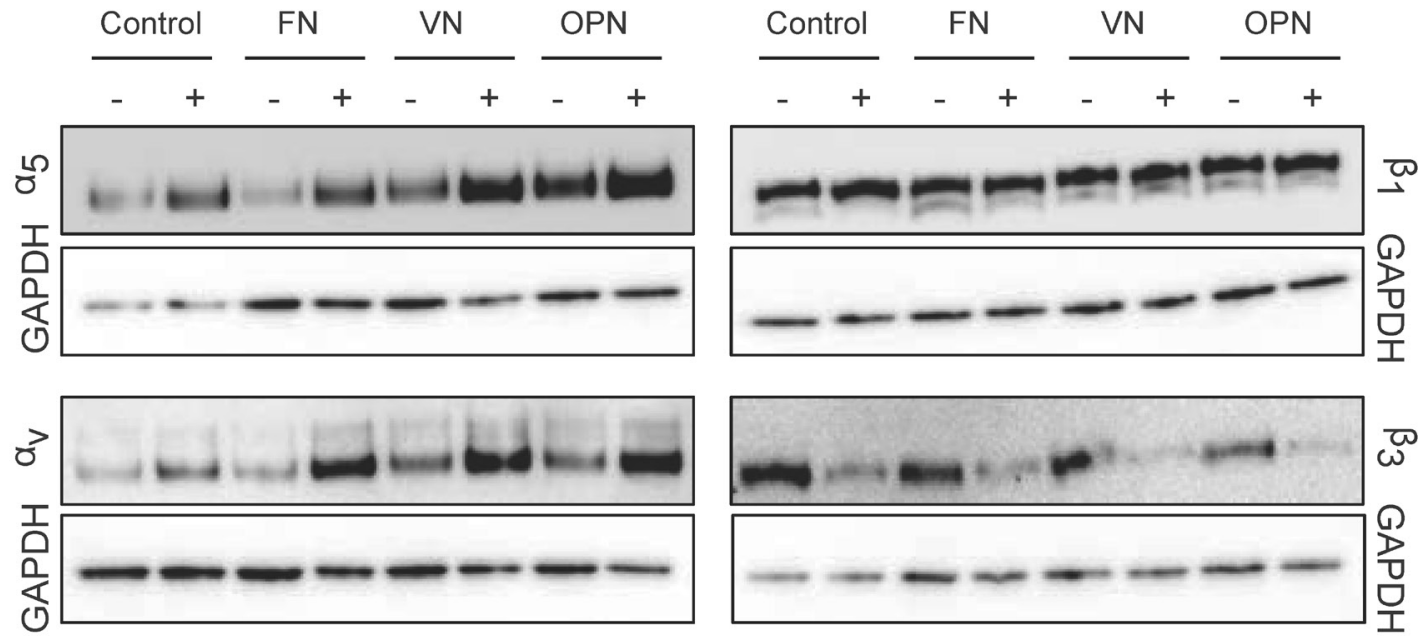

D
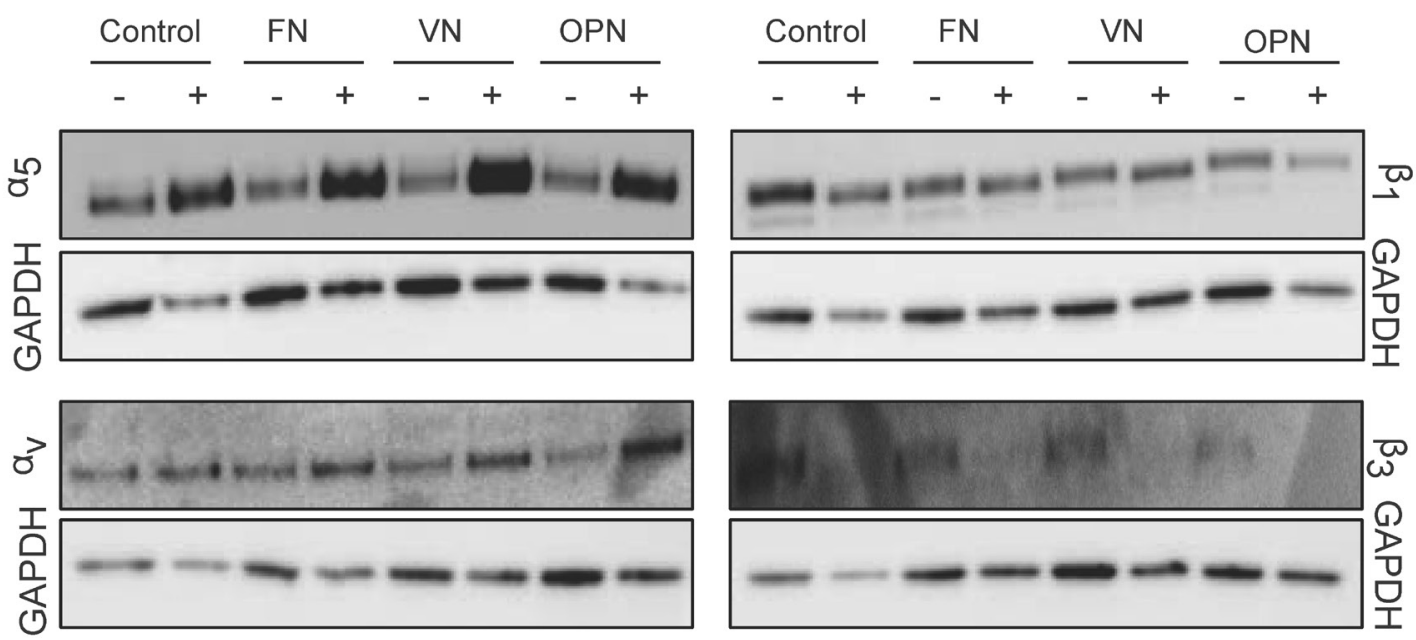

Fig 5. Integrin expression profiles in hMSCs. (A) Quantitative RT-PCR determination of integrin subunits $\left(\alpha_{v}, \alpha_{5}, \beta_{1}, \beta_{3}\right)$ at $I, 5$ and $I 0$ days after seeding hMSCs onto ECM coatings. Total RNA was harvested at the indicated time points and reverse transcribed to create a cDNA library. This was then probed using the primers shown in Materials and Methods section. (B) - (D) hMSCs cultured on ECM glycoprotein substrates for I, 5 and I0 days. After cell lysis equal protein amounts were subjected to electrophoresis and western blots were probed for the indicated proteins. GAPDH was used as loading control 


\section{Osteogenic differentiation and mineral depo- sition are elevated in MSCs cultured on FN and OPN}

The expression of cell differentiation markers was examined by quantitative RT-PCR at 1,5 and 10 days after cell seeding onto ECM coatings. As shown in Fig. 6, cells on FN express already after 5 days elevated levels of osteogenic marker genes such as BSP ( 1.5-fold) and Runx2 ( 2-fold) under osteogenic conditions. An $\sim 1.5$-fold increase in BSP and Runx2 expression is also observed in cells cultured on OPN after 10 days. However, cells cultured on VN show slightly elevated levels of osteogenic marker genes after 10 days under osteogenic conditions compared to proliferation conditions. Gene expression of ALP is low in all samples; however, highest levels are measured in cells cultured on FN under osteogenic conditions for 10 days (Fig. 6).

Alizarin Red S staining performed on day 21 to determine osteogenic induction shows a positive staining for calcium on all surfaces. The highest mineral deposition is observed in cells cultured on FN and OPN compared to VN and PLL control (Fig. 7).

\section{Discussion}

While the role of ECM in regulating cell adhesion, migration and differentiation of hMSCs has been demonstrated in several studies, the specific contribution of integrins in directing stem cell commitment remains still unclear. In this study we show the effect of ECM-derived RGD-containing glycoproteins on adhesion, proliferation, cell shape and integrin expression pattern as well as osteogenic commitment.

Our data demonstrate a strong adhesive interaction between MSCs and FN, as also reported in other studies (40-43). MSCs adhere to FN via $a_{5} \beta_{1}$-integrin and, to a minor extent, $\alpha_{v} \beta_{3}$-integrin binding (40). $\alpha_{5} \beta_{1}$-integrin promotes cell spreading, survival and proliferation (12,44-46), hence supporting our observation of an increase in cell adhesion and proliferation of MSCs on FN-coated surfaces in comparison to other ECM protein coatings. However, it should be noted that 1 day in culture on the different substrates, the number of proliferating cells on $\mathrm{FN}$ is comparable to the other ECM proteins, suggesting that the nature of initial interactions of MSCs with FN is merely adhesive. A positive effect on proliferation is first observed after 5 days in culture on FN surfaces.

Plating human MSCs on purified ECM proteins supports cell growth for at least 10 days, whereas a clear decrease in proliferation under osteogenic conditions is observed already 1 day after seeding. This is in agreement with Stein and Lian (47), who reported an upregulation of genes involved in maturation and mineralization of ECM, and a simultaneous decrease of proliferation rate, during osteoblastic differentiation.
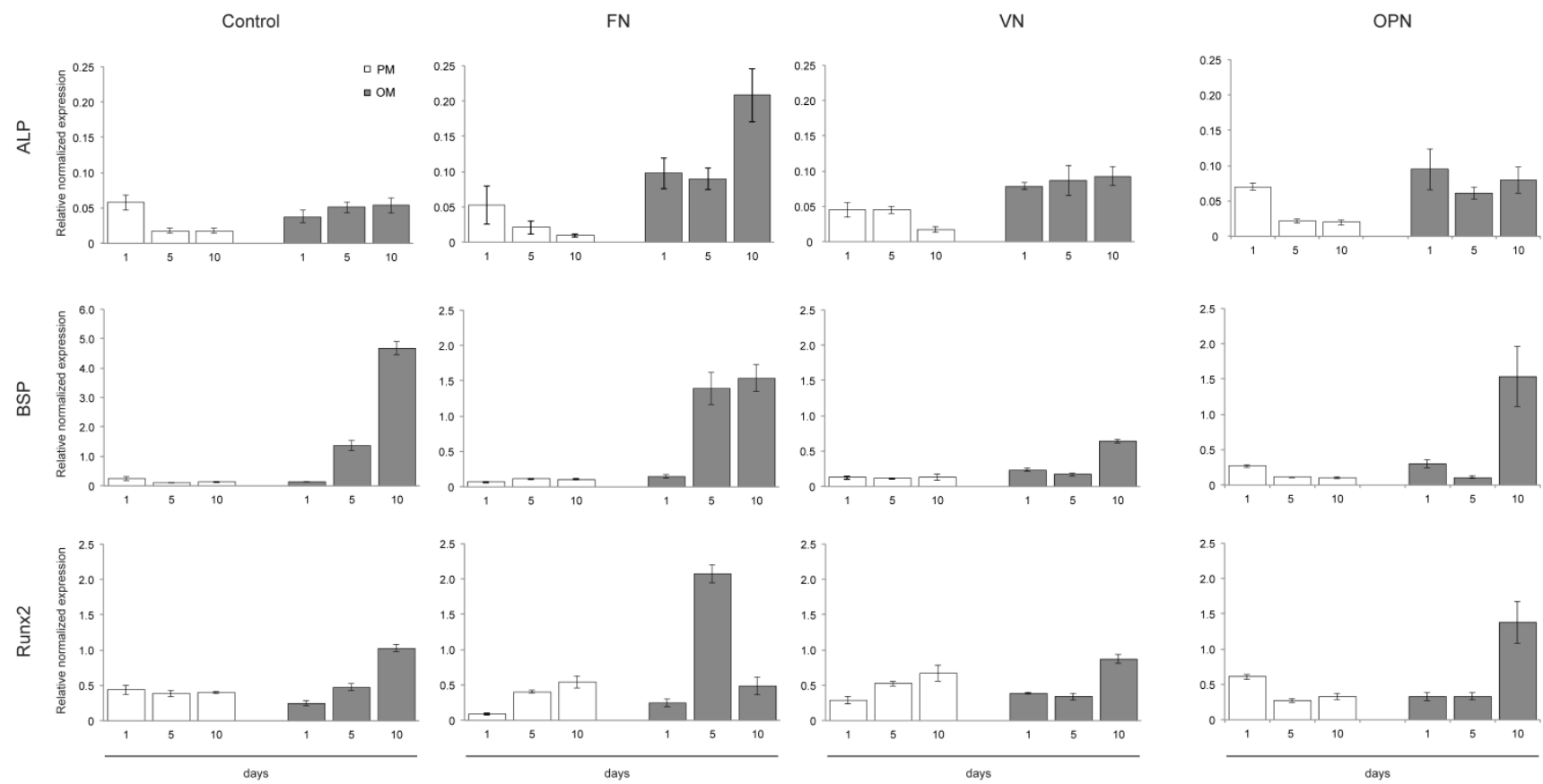

Fig 6. Osteogenic differentiation of hMSCs on substrates coated with ECM-derived RGD-glycoproteins. Quantitative RT-PCR determination of osteogenic differentiation markers (ALP, BSP, Runx2) at I, 5 and 10 days after cell seeding onto ECM coatings. Cells were cultured under either standard growth or osteogenic differentiation conditions and total RNA was isolated at the indicated time points. After reverse transcription samples were probed with primers shown in the Materials and Methods section. 

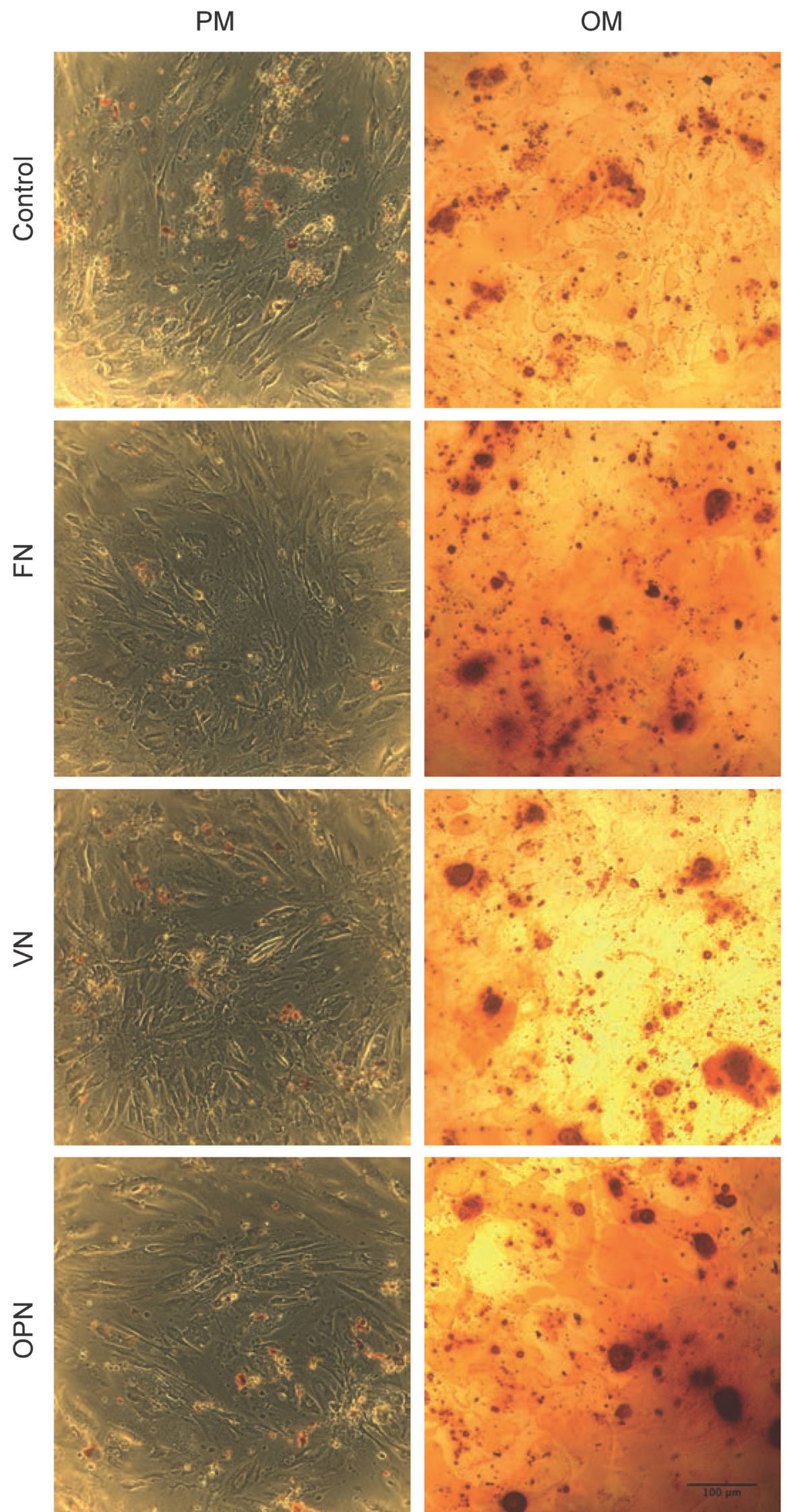

Fig 7. Histochemical staining for calcium. Phase contrast micrographs showing the staining of hMSCs on ECM-coated plates under growth and osteogenic differentiation conditions. Staining was performed using Alizarin Red S stain on day 21. 
In contrast to Ode et al. (40), we did not observe a comparable adhesion and proliferation of MSCs plated on VN and FN. This might be due to the different amount of serum and growth supplement used in both studies, which could also affect the proliferation rates after several days. Cell adhesion to VN is mediated by binding of $\alpha_{\mathrm{v}} \beta_{3}$-integrin to the RGD motif, whereas adhesion to OPN is mediated by binding of both $\alpha_{v} \beta_{3}$-integrin, and to a minor extent by $\alpha_{5} \beta_{1}$-integrin (48-50). It has been also reported that OPN promotes cell adhesion in a dose dependent manner. Under standard growth conditions, only cells on FN and OPN displayed enhanced proliferation while cells on $\mathrm{VN}$ proliferated less. Although $\alpha_{v} \beta_{3}$-integrin is the main receptor in MSCs promoting adhesion to VN and OPN $(12,51)$, it has a negative effect on the proliferation of osteoprogenitor cells. Blocking of $\alpha_{v} \beta_{3}$-integrin results in an increase in proliferation of human MSCs on FN and FN-fragments was observed (52). Thus, (i) enhanced adhesion to FN, and (ii) increased proliferation rate on FN and OPN, in comparison to $\mathrm{VN}$, may be due to the engagement of $\alpha_{5} \beta_{1}$-integrin.

The analysis of cell area revealed two major subpopulations of hMSCs and cells were divided into two groups depending on their average size (smaller and larger than $5000 \mu \mathrm{m}^{2}$ ). The predominant spindle morphology observed for cells on PLL under growth conditions may be due to a non-differentiating state in conjunction to poor adhesion. Interestingly, cells on FN and VN exhibited an increased cell area also under growth conditions. Previous studies also reported on these morphological changes $(34,53)$, however, our study provides for the first time a classification of cell area under different conditions. While differentiation may influence and induce changes in cell shape, it has been demonstrated that cell morphology could direct the differentiation of MSC (54-56). When exposed to osteogenic conditions, they underwent a morphological change and became larger, showing a flattened and cuboidal phenotype. In fact, highly spread MSCs are more prone to commit to the osteoblast lineage, whereas round shaped MSCs to the adipocyte lineage. Therefore, FAs are also important in differentiation: while osteogenesis requires larger numbers of FAs, both, adipogenesis and chondrogenesis, are promoted by preventing the formation of robust FAs (35).

Upon osteogenic stimulation, the actin cytoskeleton of hMSCs was reorganized into a more vigorous network with higher content of robust stress fibers, a process that has also been described by Yourek et al. (57). Since Lavenus et al. demonstrated a correlation between enhanced adhesion and increased FA number (42), we quantified the number of FA clusters by vinculin immunostaining. Vinculin is a plasma mem- brane associated protein found in adhesion complexes and is therefore an ideal marker protein to label integrin-mediated adhesion (58). Cells cultured on FN exhibited an enhanced adhesion and a significantly higher number of FAs under osteogenic conditions after 4 hours, whereas FA size was significantly decreased compared to other ECM protein coatings. Moreover, cells on FN and VN contained a high number of vinculin clusters located towards the cell center under osteogenic conditions, which could be considered as mature structures or fibrillar adhesions. These types of clusters are found in less motile cells, and mediate firm adhesion to the matrix and matrix assembly (59).

It has been shown that FA size correlates with the amount of force that is applied (60). The number of FA clusters per cell increased on all surfaces under growth conditions from 4 hours to 1 day, whereas the mean size of the clusters remained the same except on $\mathrm{VN}$. The increase in number of adhesion clusters indicates an enhanced adhesion to the substrates over time. Roca-Cusachs et al. (61) reported that adhesion strength is mediated mainly by $\alpha_{5} \beta_{1}$-integrins whereas integrin $\alpha_{v} \beta_{3}$ is essential for reinforcement and mechanotransduction. Under osteogenic conditions, however, cells on FN exhibited a high number of small FAs whereas after 1 day, fewer but enlarged FAs were visible within the cells. This suggests that a higher number of dynamic clusters might be needed for initial adhesion and spreading to ensure faster FA turnover. In contrast, the number of FAs on the other ECM coatings increased over time. Compared to the average area of FAs formed after 4 hours, the cluster size increased in the case of $\mathrm{VN}$ but decreased in cells cultured on OPN. Since a previous report by Gallant et al. (62) demonstrated a correlation between FA area and cell adhesion strength, this results indicates higher adhesion strength of hMSC on VN. Kundu et al. (63) also reported an increased assembly of FA correlated with increased phosphorylation of FAK and paxillin in MSCs grown on VN.

Previous studies have shown that integrin $a_{5}$ expression is increased during osteoblastic differentiation and furthermore, overexpression of this integrin subunit was enough to induce osteogenic differentiation in MSCs (26). However, Cheng et al. (64) showed that dexamethasone regulates $\alpha_{v} \beta_{3}$ - and $\alpha_{5} \beta_{1}$-integrins in human osteoblastic cells and Salasznyk et al. (65) proposed that activation of $a_{v}$-integrin through adhesion to $\mathrm{VN}$ is sufficient for promoting osteogenic differentiation, even in the absence of further osteogenic stimuli. Ode et al. (40) also suggested a connection between specific integrin expression and cell commitment but, in contrast to Salasznyk et al., could not find a promoting role of $\mathrm{VN}$ in osteoblastic differen- 
tiation. Although these reports show an involvement of integrin-mediated signaling pathways in the regulation of osteoblastic differentiation some of the results are still a matter of debate.

In this study, we report on differences in integrin gene expression as well as integrin protein levels depending on ECM substrates and culture conditions. We observed an upregulation of $a_{5^{-}}$and $a_{v^{-}}$integrin subunits under osteogenic conditions on all ECM coatings whereas both subunits were downregulated under growth conditions. While $a_{5}$ expression was maximal on $\mathrm{FN}, \mathrm{a}_{\mathrm{v}}$ was clearly enhanced on $\mathrm{VN}$ and especially on OPN. This result was also confirmed by western blot, therefore proving that elevated expression levels resulted in increased protein amounts in the cells.

The expression of cell differentiation markers was examined by quantitative RT-PCR at 1, 5 and 10 days after cell seeding onto ECM coatings. ALP is a cell-surface glycoprotein that is involved in mineralization process. BSP is a protein, which binds cell-surface integrin receptors after being secreted and regulates mineralization of ECM. Runx2 (Cbfa1), a member of the runt homology domain transcription factor family, is the earliest and most specific marker of osteoblast differentiation known. Functional studies have shown that it is a central regulator of osteoblast differentiation and function (36-39). The gene expression profile of cells cultured on FN and OPN showed elevated levels of BSP and Runx2. Therefore, it is evident that a relatively higher expression of these genes contributes to higher mineral deposition, which was seen after 21 days.

Therefore, these results support the findings of Hamidouche et al. (26) and further suggest a positive effect of either enhanced $a_{5}$ levels alone, or increased $a_{5}$ and $a_{v}$ levels on osteoblastic differentiation. Elevated levels of $a_{v}$ alone, however, do not seem to promote osteogenic differentiation.

\section{Conclusion}

The results of this study indicate that when MSCs adhere to the RGD-containing glycoproteins $\mathrm{FN}, \mathrm{VN}$ and OPN, $a_{\mathrm{v}} \beta_{3^{-}}$and $\alpha_{5} \beta_{1}$-integrins differentially regulate cell adhesion, phenotype and differentiation. In particular, $\beta_{1}$-integrins appear to be the predominant receptor utilized by MSCs to adhere and proliferate. For the local regulation of integrin-mediated structures and linkage to the actin cytoskeleton, $\beta_{3}$-integrins are utilized by MSCs as dominant receptor. Furthermore, these data suggest a possible role for the $\beta_{1}$-integrins during the commitment of MSCs to osteoblast lineage, whereas $\beta_{3}$-integrins seem to suppress such process. Hence, future studies with engineered fragments and pep- tides derived from matrix glycoproteins commonly found in bone marrow microenvironment and bone matrix might be useful to specifically address these integrins and further elucidate their role in MSCs differentiation in regenerative medicine applications.

\section{Supplementary Material}

Fig.S1-S2. http://www.medsci.org/v10p1846s1.pdf

\section{Abbreviations}

hMSCs: human mesenchymal stem cells; ECM: extracellular matrix; FA: focal adhesion; FN: fibronectin; OPN: osteopontin; PLL: poly-L-lysine; VN: vitronectin; ALP: alkaline phosphatase; BSP: bone sialoprotein; Runx2: runt-related transcription factor 2.

\section{Acknowledgement}

The authors thank Dr. Oksana Raabe (JLU Giessen) and Dr. Rebecca Medda (PCI Heidelberg) for reading the manuscript. This work was funded by the German Research Foundation (DFG SFB-TRR79 project B5 S.W. and E.A.C.A.). We gratefully acknowledge the support from the Max Planck Society.

\section{Competing Interests}

The authors have declared that no competing interest exists.

\section{References}

1. Kuhn NZ, Tuan RS. Regulation of stemness and stem cell niche of mesenchymal stem cells: implications in tumorigenesis and metastasis. J. Cell. Physiol. 2010 Feb;222(2):268-277.

2. Marinucci L, Balloni S, Becchetti E, Bistoni G, Calvi EM, Lumare E, et al. Effects of hydroxyapatite and Biostite on osteogenic induction of hMSC. Ann Biomed Eng. 2010 Mar;38(3):640-648.

3. Dezawa M, Ishikawa H, Itokazu Y, Yoshihara T, Hoshino M, Takeda S-I, et al. Bone marrow stromal cells generate muscle cells and repair muscle degeneration. Science. 2005 Jul 8;309(5732):314-317.

4. Engler AJ, Sen S, Sweeney HL, Discher DE. Matrix elasticity directs stem cell lineage specification. Cell. 2006 Aug 25;126(4):677-689.

5. De Bari C, Dell'Accio F, Vandenabeele F, Vermeesch JR, Raymackers J-M, Luyten FP. Skeletal muscle repair by adult human mesenchymal stem cells from synovial membrane. J. Cell Biol. 2003 Mar 17;160(6):909-918.

6. Biver E, Soubrier A-S, Thouverey C, Cortet B, Broux O, Caverzasio J, et al. Fibroblast growth factor 2 inhibits up-regulation of bone morphogenic proteins and their receptors during osteoblastic differentiation of human mesenchymal stem cells. Biochem. Biophys. Res. Commun. 2012 Nov 2;427(4):737-742.

7. Cheng SL, Yang JW, Rifas L, Zhang SF, Avioli LV. Differentiation of human bone marrow osteogenic stromal cells in vitro: induction of the osteoblast phenotype by dexamethasone. Endocrinology. 1994 Jan;134(1):277-286.

8. Pittenger MF, Mackay AM, Beck SC, Jaiswal RK, Douglas R, Mosca JD, et al. Multilineage potential of adult human mesenchymal stem cells. Science. 1999 Apr 2;284(5411):143-147.

9. Kolf CM, Cho E, Tuan RS. Mesenchymal stromal cells. Biology of adult mesenchymal stem cells: regulation of niche, self-renewal and differentiation. Arthritis Res. Ther. 2007;9(1):204.

10. Chen X-D, Dusevich V, Feng JQ, Manolagas SC, Jilka RL. Extracellular matrix made by bone marrow cells facilitates expansion of marrow-derived mesenchymal progenitor cells and prevents their differentiation into osteoblasts. J. Bone Miner. Res. 2007 Dec;22(12):1943-1956.

11. Chen X-D. Extracellular matrix provides an optimal niche for the maintenance and propagation of mesenchymal stem cells. Birth Defect Res C. 2010 Mar;90(1):45-54.

12. Shekaran A, García AJ. Extracellular matrix-mimetic adhesive biomaterials for bone repair. J. Biomed. Mater. Res. 2011 Jan;96(1):261-272. 
13. Luo B-H, Springer TA. Integrin structures and conformational signaling. Curr. Opin. Cell Biol. 2006 Oct;18(5):579-586.

14. Humphries JD, Byron A, Humphries MJ. Integrin ligands at a glance. J. Cell. Sci. 2006 Oct 1;119(Pt 19):3901-3903.

15. Hynes RO. Integrins: bidirectional, allosteric signaling machines. Cell. 2002 Sep 20;110(6):673-687.

16. Denhardt DT, Guo X. Osteopontin: a protein with diverse functions. FASEB J. 1993 Dec;7(15):1475-1482

17. Porter JR, Ruckh TT, Popat KC. Bone tissue engineering: a review in bone biomimetics and drug delivery strategies. Biotechnol. Prog. 2009 Oct;25(6):1539-1560.

18. Degasne I, Baslé MF, Demais V, Huré G, Lesourd M, Grolleau B, et al. Effects of roughness, fibronectin and vitronectin on attachment, spreading, and proliferation of human osteoblast-like cells (Saos-2) on titanium surfaces. Calcif. Tissue Int. 1999 Jun;64(6):499-507.

19. Chen CS, Mrksich M, Huang S, Whitesides GM, Ingber DE. Geometric control of cell life and death. Science. 1997 May 30;276(5317):1425-1428.

20. Roskelley CD, Desprez PY, Bissell MJ. Extracellular matrix-dependent tissue-specific gene expression in mammary epithelial cells requires both physical and biochemical signal transduction. Proc. Natl. Acad. Sci. U.S.A. 1994 Dec 20;91(26):12378-12382.

21. McBeath R, Pirone DM, Nelson CM, Bhadriraju K, Chen CS. Cell shape, cytoskeletal tension, and RhoA regulate stem cell lineage commitment. Dev. Cell. 2004 Apr;6(4):483-495.

22. Gumbiner BM. Cell adhesion: the molecular basis of tissue architecture and morphogenesis. Cell. 1996 Feb 9;84(3):345-357.

23. Cheng SL, Lai CF, Blystone SD, Avioli LV. Bone mineralization and osteoblast differentiation are negatively modulated by integrin alpha(v)beta3. J. Bone Miner. Res. 2001 Feb;16(2):277-288.

24. El-Amin SF, Attawia M, Lu HH, Shah AK, Chang R, Hickok NJ, et al. Integrin expression by human osteoblasts cultured on degradable polymeric materials applicable for tissue engineered bone. J. Orthop. Res. 2002 Jan;20(1):20-28.

25. Schneider GB, Zaharias R, Stanford C. Osteoblast integrin adhesion and signaling regulate mineralization. J. Dent. Res. 2001 Jun;80(6):1540-1544.

26. Hamidouche $\mathrm{Z}$, Fromigué $\mathrm{O}$, Ringe $\mathrm{J}$, Häupl $\mathrm{T}$, Vaudin $\mathrm{P}$, Pagès J-C, et al. Priming integrin alpha5 promotes human mesenchymal stromal cell osteoblast differentiation and osteogenesis. Proc. Natl. Acad. Sci. U.S.A. 2009 Nov 3;106(44):18587-18591.

27. Huang GT-J, Gronthos S, Shi S. Mesenchymal stem cells derived from dental tissues vs. those from other sources: their biology and role in regenerative medicine. J. Dent. Res. 2009 Sep;88(9):792-806.

28. Colter DC, Class R, DiGirolamo CM, Prockop DJ. Rapid expansion of recycling stem cells in cultures of plastic-adherent cells from human bone marrow. Proc. Natl. Acad. Sci. U.S.A. 2000 Mar 28;97(7):3213-3218.

29. Santiago JA, Pogemiller R, Ogle BM. Heterogeneous differentiation of human mesenchymal stem cells in response to extended culture in extracellular matrices. Tissue Eng Part A. 2009 Dec;15(12):3911-3922.

30. DiGirolamo CM, Stokes D, Colter D, Phinney DG, Class R, Prockop DJ. Propagation and senescence of human marrow stromal cells in culture: a simple colony-forming assay identifies samples with the greatest potential to propagate and differentiate. Br. J. Haematol. 1999 Nov;107(2):275-281.

31. Colter DC, Sekiya I, Prockop DJ. Identification of a subpopulation of rapidly self-renewing and multipotential adult stem cells in colonies of human marrow stromal cells. Proc. Natl. Acad. Sci. U.S.A. 2001 Jul 3;98(14):7841-7845.

32. Sekiya I, Larson BL, Smith JR, Pochampally R, Cui J-G, Prockop DJ. Expansion of human adult stem cells from bone marrow stroma: conditions that maximize the yields of early progenitors and evaluate their quality. Stem Cells. 2002;20(6):530-541.

33. Smith JR, Pochampally R, Perry A, Hsu S-C, Prockop DJ. Isolation of a highly clonogenic and multipotential subfraction of adult stem cells from bone marrow stroma. Stem Cells. 2004;22(5):823-831.

34. Docheva D, Padula D, Popov C, Mutschler W, Clausen-Schaumann $\mathrm{H}_{\text {, }}$ Schieker M. Researching into the cellular shape, volume and elasticity of mesenchymal stem cells, osteoblasts and osteosarcoma cells by atomic force microscopy. J. Cell. Mol. Med. 2008 Apr;12(2):537-552.

35. Mathieu PS, Loboa EG. Cytoskeletal and focal adhesion influences on mesenchymal stem cell shape, mechanical properties, and differentiation down osteogenic, adipogenic, and chondrogenic pathways. Tissue Eng Part B Rev. 2012 Dec;18(6):436-444.

36. Marom R, Shur I, Solomon R, Benayahu D. Characterization of adhesion and differentiation markers of osteogenic marrow stromal cells. J. Cell. Physiol. 2004;202(1):41-48.

37. Aubin JE. Regulation of osteoblast formation and function. Rev Endocr Metab Disord. 2001 Jan;2(1):81-94.

38. Karsenty G, Ducy P, Starbuck M, Priemel M, Shen J, Geoffroy V, et al. Cbfa1 as a regulator of osteoblast differentiation and function. Bone. 1999 Jul;25(1):107-108.

39. Karsenty G. The genetic transformation of bone biology. Genes Dev. 1999 Dec 1;13(23):3037-3051.

40. Ode A, Duda GN, Glaeser JD, Matziolis G, Frauenschuh S, Perka C, et al. Toward biomimetic materials in bone regeneration: functional behavior of mesenchymal stem cells on a broad spectrum of extracellular matrix components. J. Biomed. Mater. Res. 2010 Dec 15;95(4):1114-1124.

41. Klees RF, Salasznyk RM, Kingsley K, Williams WA, Boskey A, Plopper GE. Laminin-5 Induces Osteogenic Gene Expression in Human Mesenchymal
Stem Cells through an ERK-dependent Pathway. Mol. Biol. Cell. 2005 Feb 1;16(2):881-890.

42. Lavenus S, Pilet P, Guicheux J, Weiss P, Louarn G, Layrolle P. Behaviour of mesenchymal stem cells, fibroblasts and osteoblasts on smooth surfaces. Acta Biomater. 2011 Apr;7(4):1525-1534.

43. Gronthos S, Simmons PJ, Graves SE, Robey PG. Integrin-mediated interactions between human bone marrow stromal precursor cells and the extracellular matrix. Bone. 2001 Feb;28(2):174-181.

44. Damsky CH. Extracellular matrix-integrin interactions in osteoblast function and tissue remodeling. Bone. 1999 Jul;25(1):95-96.

45. Matter ML, Ruoslahti E. A signaling pathway from the alpha5beta1 and alpha(v)beta3 integrins that elevates bcl-2 transcription. J. Biol. Chem. $2001 \mathrm{Jul}$ 27;276(30):27757-27763

46. Howe AK, Aplin AE, Juliano RL. Anchorage-dependent ERK signaling--mechanisms and consequences. Curr. Opin. Genet. Dev. 2002 Feb;12(1):30-35.

47. Stein GS, Lian JB. Molecular mechanisms mediating proliferation/differentiation interrelationships during progressive development of the osteoblast phenotype. Endocr. Rev. 1993 Aug;14(4):424-442.

48. Shin H, Zygourakis K, Farach-Carson MC, Yaszemski MJ, Mikos AG. Attachment, proliferation, and migration of marrow stromal osteoblasts cultured on biomimetic hydrogels modified with an osteopontin-derived peptide. Biomaterials. 2004 Feb;25(5):895-906.

49. Somerman MJ, Prince CW, Butler WT, Foster RA, Moehring JM, Sauk JJ. Cell attachment activity of the 44 kilodalton bone phosphoprotein is not restricted to bone cells. Matrix. 1989 Jan;9(1):49-54.

50. Takada Y, Ye X, Simon S. The integrins. Genome Biol. 2007;8(5):215.

51. Sodek J, Ganss B, McKee MD. Osteopontin. Crit. Rev. Oral Biol. Med. 2000;11(3):279-303

52. Martino MM, Mochizuki M, Rothenfluh DA, Rempel SA, Hubbell JA, Barker $\mathrm{TH}$. Controlling integrin specificity and stem cell differentiation in 2D and 3D environments through regulation of fibronectin domain stability. Biomaterials. 2009 Feb;30(6):1089-1097.

53. Jaiswal N, Haynesworth SE, Caplan AI, Bruder SP. Osteogenic differentiation of purified, culture-expanded human mesenchymal stem cells in vitro. J. Cell. Biochem. 1997 Feb;64(2):295-312.

54. Gao L, McBeath R, Chen CS. Stem cell shape regulates a chondrogenic versus myogenic fate through Rac1 and N-cadherin. Stem Cells. 2010 Mar 31;28(3):564-572.

55. Peng R, Yao X, Ding J. Effect of cell anisotropy on differentiation of stem cells on micropatterned surfaces through the controlled single cell adhesion. Biomaterials. 2011 Nov;32(32):8048-8057.

56. Peng R, Yao X, Cao B, Tang J, Ding J. The effect of culture conditions on the adipogenic and osteogenic inductions of mesenchymal stem cells on micropatterned surfaces. Biomaterials. 2012 Sep;33(26):6008-6019.

57. Yourek G, Hussain MA, Mao JJ. Cytoskeletal changes of mesenchymal stem cells during differentiation. ASAIO J. 2007 Feb;53(2):219-228

58. Critchley DR. Focal adhesions - the cytoskeletal connection. Curr. Opin. Cell Biol. 2000 Feb;12(1):133-139.

59. Zamir E, Geiger B. Molecular complexity and dynamics of cell-matrix adhesions. J. Cell. Sci. 2001 Oct;114(Pt 20):3583-3590.

60. Trichet L, Le Digabel J, Hawkins RJ, Vedula SRK, Gupta M, Ribrault C, et al. Evidence of a large-scale mechanosensing mechanism for cellular adaptation to substrate stiffness. Proceedings of the National Academy of Sciences. 2012 May 1;109(18):6933-6938.

61. Roca-Cusachs P, Gauthier NC, Del Rio A, Sheetz MP. Clustering of alpha(5)beta(1) integrins determines adhesion strength whereas alpha(v)beta(3) and talin enable mechanotransduction. Proceedings of the National Academy of Sciences. 2009 Sep 22;106(38):16245-16250.

62. Gallant ND, Michael KE, García AJ. Cell adhesion strengthening: contributions of adhesive area, integrin binding, and focal adhesion assembly. Mol. Biol. Cell. 2005 Sep;16(9):4329-4340.

63. Kundu AK, Putnam AJ. Vitronectin and collagen I differentially regulate osteogenesis in mesenchymal stem cells. Biochem. Biophys. Res. Commun. 2006 Aug:347(1):347-357.

64. Cheng SL, Lai CF, Fausto A, Chellaiah M, Feng X, McHugh KP, et al. Regulation of alphaVbeta 3 and alphaVbeta 5 integrins by dexamethasone in normal human osteoblastic cells. J. Cell. Biochem. 2000 Mar;77(2):265-276.

65. Salasznyk RM, Williams WA, Boskey A, Batorsky A, Plopper GE. Adhesion to Vitronectin and Collagen I Promotes Osteogenic Differentiation of Human Mesenchymal Stem Cells. J. Biomed. Biotech. 2004;2004(1):24-34 